\title{
A Systematic Review and Meta-Analysis on the Survival of Cancer Patients Treated with a Fermented Viscum album L. Extract (Iscador): An Update of Findings
}

\author{
Thomas Ostermann ${ }^{a}$ Sebastian Appelbaum ${ }^{a}$ Désirée Poier ${ }^{b} \quad K^{2}$ tja Boehm ${ }^{a}$ \\ Christa Raak $^{\mathrm{b}}$ Arndt Büssing ${ }^{\mathrm{b}}$ \\ ${ }^{a}$ Chair of Research Methodology and Statistics, Faculty of Health, Witten/Herdecke University, Witten, Germany; \\ b Institute of Integrative Medicine, Faculty of Health, Witten/Herdecke University, Herdecke, Germany
}

\section{Keywords}

Viscum album · Mistletoe · Iscador · Survival · Meta-analysis

\begin{abstract}
Purpose: We aimed at updating the evidence found in controlled studies addressing general and event-free survival of cancer patients treated with the fermented mistletoe extract Iscador. Methods: The databases Embase, PubMed, CAMbase, Scopus, AMED and Cochrane were searched for clinical studies on cancer patients treated with Iscador. Quality of studies and risk of bias were evaluated according to the Cochrane guidelines and the Newcastle Ottawa Scale. Outcome data were expressed as hazard ratios (HR) and the respective $95 \%$ confidence intervals $(\mathrm{Cl})$. Meta-analysis was carried out using a random-effects model. Results: Eightytwo controlled studies met the inclusion criteria, of which 32 with 55 strata provided data for extracting $\mathrm{HR}$ and $\mathrm{Cl}$. The overall HR was 0.59 (95\% Cl: [0.53; 0.65], $p<0.0001)$ in favour of Iscador treatment. Heterogeneity of study results was moderate $\left(I^{2}=50.9 \% ; p<0.0001, \tau^{2}=0.053\right)$. Meta-regression did not reveal significant effects of sample size or study design. However, significant differences were found between cancer entities $(p<0.01)$, with most pronounced effects in cervical $(\mathrm{HR}=0.43)$ and less pronounced effects in lung cancer $(H R=0.84)$. Conclusions: We found almost identical ef-
\end{abstract}

\section{karger@karger.com}

www.karger.com/cmr

Karger $\stackrel{\text { '⿳亠丷厂 }}{=}$
(C) 2020 The Author(s)

Published by S. Karger AG, Basel

Karger

Open access

This article is licensed under the Creative Commons AttributionNonCommercial-NoDerivatives 4.0 International License (CC BYNC-ND) (http://www.karger.com/Services/OpenAccessLicense). Usage and distribution for commercial purposes as well as any distribution of modified material requires written permission. fects on cancer survival based on a broader database of higher quality. However, none of the studies was blinded and, therefore, there might be risk of performance bias. Implications for cancer survivors are as follows: findings indicate that adjuvant treatment of cancer patients with Iscador can be associated with a better survival.

(C) 2020 The Author(s)

Published by S. Karger AG, Basel

Eine Systematische Übersicht und Meta-Analyse zum Überleben von Krebspatienten, die mit einem Fermentiertem Viscum-Album-L.-Extrakt behandelt wurden: Ein Ergebnis-Update

\section{Schlüsselwörter}

Viscum album · Mistel · Iscador · Überleben .

Meta-Analyse

\section{Zusammenfassung}

Ziel der Untersuchung: Unser Ziel war die Aktualisierung der Wirksamkeitseinschätzung des fermentierten MistelExtrakts Iscador in kontrollierten Studien auf das Gesamtoder Ereignis-freie Überleben von Krebspatienten. Methoden: Die Datenbanken Embase, PubMed, CAMbase, 
Scopus, AMED und Cochrane wurden nach klinischen Studien mit Krebspatienten durchsucht, die mit Iscador behandelt wurden. Die Studienqualität und das Verzerrungsrisiko wurden gemäß der Cochrane-Leitlinien und der Newcastle-Ottawa-Skala beurteilt. Die Ergebnisdaten wurden als Hazard Ratios (HR) und die jeweiligen 95\%-Konfidenzintervalle $(\mathrm{Cl})$ ausgedrückt. Die Meta-Analyse wurde mit einem Zufallseffektmodell durchgeführt. Ergebnisse: 82 kontrollierte Studien erfüllten die Einschlusskriterien, von denen 32 mit 55 Strata Daten für die Ermittlung der $\mathrm{HR}$ und $\mathrm{Cl}$ lieferten. Die gesamt-HR betrug 0,59 ( $\mathrm{Cl}: 0,53$ bis $0,65, p<0.0001$ ) zugunsten der Iscador-Behandlung. Die Heterogenität der Studienergebnisse war moderat $\left(I^{2}=\right.$ $\left.50.9 \% ; p<0.0001, \mathrm{t}^{2}=0.053\right)$. Die Meta-Regression zeigte keinen signifikanten Einfluss des Stichprobenumfangs oder des Studiendesigns. Allerdings wurden signifikante Unterschiede zwischen den Krebsarten $(p<0.01)$ festgestellt, mit den stärksten Effekten bei Gebärmutterhalskrebs $(H R=0.43)$ und weniger starken Effekten bei Lungenkrebs ( $H R=0.84)$. Schlussfolgerungen: Diese Aktualisierung ergab fast identische Effekte in der Überlebenszeit Krebserkrankter, die auf einer breiteren Datenbasis mit höherer Qualität basierten. Allerdings war keine der Studien verblindet, so dass das Risiko einer Performance-Verzerrung bestehen könnte. Dies sind die Auswirkungen auf das Überleben Krebserkrankter: Die Ergebnisse deuten darauf hin, dass die adjuvante Behandlung von Krebspatienten mit Iscador mit einem besseren Überleben verbunden sein kann.

(c) 2020 The Author(s) Published by S. Karger AG, Basel

\section{Introduction}

Cancer is one of the most challenging diseases worldwide. The International Agency for Research on Cancer in 2012 reported an estimated 5-year prevalence of 32,455,000 cases worldwide for all cancers (excluding non-melanoma skin cancer). The World Health Organization reported 14.1 million new cancer cases worldwide in 2012 and projected an increase in annual cancer deaths to 12.6 million in 2030 [1]

The findings of Horneber et al. [2] suggest that "on average, half of all cancer patients use CAM [Complementary and Alternative Medicine]" and that this proportion has increased over the past years (p.9). Following the definition of the National Center for Complementary and Alternative Medicine (NCCAM) [3], Kooreman and Baars [4] defined CAM as "a group of diverse medical and health care systems, practices and products that are not generally considered part of conventional medicine" ( $p$. 769). Patients are motivated to use complementary treatments based on, for example, the hope for a longer survival, the wish for a higher tolerability of cancer therapy or a higher quality of life [5]. There has also been an increased interest of researchers in CAM in recent years [6].

Plant extract preparations from European mistletoe (Viscum album L.) have been examined as supportive cancer treatment in clinical studies particularly in Western Europe for more than 50 years. In the 1920s, the philosopher Rudolf Steiner (1861-1925), founder of anthroposophic medicine, introduced the use of mistletoe extract in oncology [7]. Mistletoes grow as an evergreen shrub on different host trees [8]. Various mistletoe preparations, differing with respect to their extraction process (i.e., aqueous fermentation, water extraction, pressing) and thus to the proportion of relevant ingredients (particularly mistletoe lectins, viscotoxins and polysaccharides), may be obtained as injectable prescriptions and are or were used for subcutaneous cancer treatment, e.g., abnobaVISCUM, Cefalektin, Eurixor, Helixor, Iscador, Iscucin, Isorel and Lektinol [9]. The first breast cancer patient was treated with a mistletoe preparation by Ita Wegman, a Dutch physician, soon after its recommendation by Rudolf Steiner at the beginning of the last century [10]. At that time, there was nearly no pharmacological research on the effects of mistletoe extract application and only some single case studies. Today, mistletoe preparations are used in addition to conventional treatment to reduce side effects of cancer treatment or to support the convalescence of patients [5]. It has been found to be a safe treatment with just mild to moderate adverse drug reactions in cancer patients [11].

For practicing physicians, therapists and patients, the expanding field of publications makes it difficult to keep an overview of treatment options. The pooling of information on treatments and the evidence of their effectiveness is a necessary basis for a shared decision-making for practitioners and patients in the disease process [12]. In recent years, a number of systematic reviews on the effectiveness of mistletoe focusing on various aspects of mortality, morbidity and quality of life were published [1214]. However, due to the diversity of mistletoe products resulting from differences in production conditions, the proportions of their pharmacologically relevant constituents are diverse, rendering the interpretation of clinical study outcomes difficult. For example, abnobaVISCUM extracts are produced by aqueous maceration of fresh plant material; Helixor and Isorel use cold water extraction; Iscador extracts are based on lactic fermentation of plant material; Iscucin is produced in accordance with the German Homeopathic Pharmacopoeia [9].

Therefore, our 2009 systematic literature review was the first to focus exclusively on the survival of cancer patients treated with the mistletoe extract Iscador [12], which is the most commonly applied mistletoe extract preparation, instead of combining data from studies with different mistletoe extracts. Iscador is a fermented prepa- 
ration of plants from the winter and summer harvest and contains a high amount of cytotoxic mistletoe lectins and viscotoxins $[9,15]$. It is available from mistletoes grown on different host trees (i.e., from oak, pine and apple tree), which all may slightly differ in their content of cytotoxic mistletoe lectins.

For this systematic review and meta-analysis, we again focused on Iscador extracts because they are widely used and published studies are available since the 1960s. Since Iscador is used as a general cancer treatment, all tumour entities have been included in the analysis. We aimed to update the results of the first systematic literature review on general and event-free survival of cancer patients and to extend the quality assessment analyses.

\section{Methods}

A literature research for studies that address the effects of Iscador extracts on overall or event-free survival of cancer patients was performed between November 2015 and February 2016. The following electronic databases were used: PubMed/Medline, Embase, the Cochrane Library/the Cochrane central register of controlled trials (CENTRAL), AMED, CAMbase and Scopus. We also searched the database of the journal Der Merkurstab. Concurrently, experts in the field of mistletoe and anthroposophic medicine were contacted for other publications that were not found in the public databases. Each database was searched from its inception through February 2016. Additionally, reference lists of systematic reviews on mistletoe research and a documentation of published clinical studies with Iscador of the "Verein für Krebsforschung" [16] were screened for further hits.

The systematic literature research was based on the separate search terms of the first review published in 2009: "Iscador" and "study," "mistletoe" and "study," and "viscum" and "study." If necessary, the equivalent translations in German language were used. In the databases Embase and the Cochrane Library/CENTRAL, the search was restricted to articles in German and English language and to the topics "human" and "cancer." The reporting of the results adhered, if possible and appropriate, to the Preferred Reporting Items for Systematic Reviews and Meta-Analyses (PRISMA) guidelines [17] and to the Cochrane Handbook for Systematic Reviews of Interventions, version 5.2.0 [18].

\section{Inclusion and Exclusion Criteria}

We searched for controlled clinical studies reporting on parameters associated with general and event-free survival (i.e., disease-free, progression-free or relapse-free survival, or time to these events) in German or English language. The publications included in the first systematic review by Ostermann et al. [12] were also integrated in the meta-analyses. Opinion articles, Master or Bachelor theses, documentations, comments, and theoretical essays and field reports were not included. We excluded studies without any control group, case reports, translations of already published manuscripts, abstracts which proceeded a full-length publication, double publications of the same data (except publications reporting on further data), publications reporting on interim analyses when total results were published in another publication, internal reports and unpublished reports. Publications were also excluded when the control group also received the Iscador treatment, or when mistletoe extract preparations other than Iscador where used, too.

\section{Data Extraction and Analysis}

Two authors assessed trials for inclusion in the review. The retrieved articles were fully read and checked for compliance with the selection criteria. Studies were classified with respect to year of publication, number of patients, tumour localisation and staging, study type and randomization. Extraction of data and the evaluation of quality assessment were executed by 2 reviewers independently. Disagreements were resolved by consensus.

\section{Quality Assessment}

For the evaluation of study quality of randomized studies, a checklist (rater assessment) based on common instruments, such as the JADAD score or the CONSORT criteria, and the Cochrane Handbook for Systematic Reviews of Interventions, version 5.2.0 [18] were used. In addition, the criteria of the first review of 2009 were integrated in the checklist used for this systematic review and meta-analysis. The non-randomized studies were evaluated by the Newcastle-Ottawa scale [19]. This scale considers 3 domains: the "selection domain," the "comparability domain" and the "outcome/exposure domain," contributing maximally 4, 2 and 3 stars, respectively, yielding an overall score of maximally 9 stars.

\section{Statistical Analysis}

Data were analysed using the R package "Metafor" [20] and "meta" [21]. Outcome data were extracted as hazard ratios (HR) with $95 \%$ confidence interval (CI), their logarithms and the respective standard errors. If HRs were not given explicitly, the assumption of exponentially distributed overall survival times was made allowing to estimate HRs, even if only median survival times, mean survival times or (preferentially 5-year) survival rates were given in the publication [20]. In case of no events in 1 study arm, a constant of 0.5 was added. In our case, $\mathrm{HR}<1$ indicates superiority of Iscador, HR $>1$ indicates superiority of the control condition.

For meta-analysis of survival results, HRs were pooled to provide an aggregate value. To test heterogeneity of included studies, Cochran's test was used and the heterogeneity index $I^{2}$ and the between-study variance $\tau^{2}$ were calculated. $p$ values $<0.05$ were considered to indicate significance. Since heterogeneity between individual studies turned out to be significantly different, a random-effects model was used to pool the estimate across studies with the DerSimonian-Laird method whereby studies were assumed to be randomly chosen from an underlying normally distributed population. To explore the impact of publication year, cancer location and sample size, a random-effects model metaregression analysis for each variable was performed. We also performed subgroup analysis for study type, newly included studies and cancer location. We finally investigated the publication bias for overall survival meta-analyses with a visual inspection of funnel plots and with Egger's regression test for funnel plot asymmetry.

\section{Results}

After removal of duplicates, a total of 188 potentially relevant citations were reviewed (Fig. 1). Of those, 64 articles were excluded because they used other Viscum album extracts from different manufacturers, or combinations of Iscador with other treatments, or the respective data were not available or unclear. In the next step, we excluded 42 studies on Iscador usage, which were not focusing on survival as outcome. The remaining studies report survival data of patients treated with Iscador. Among 


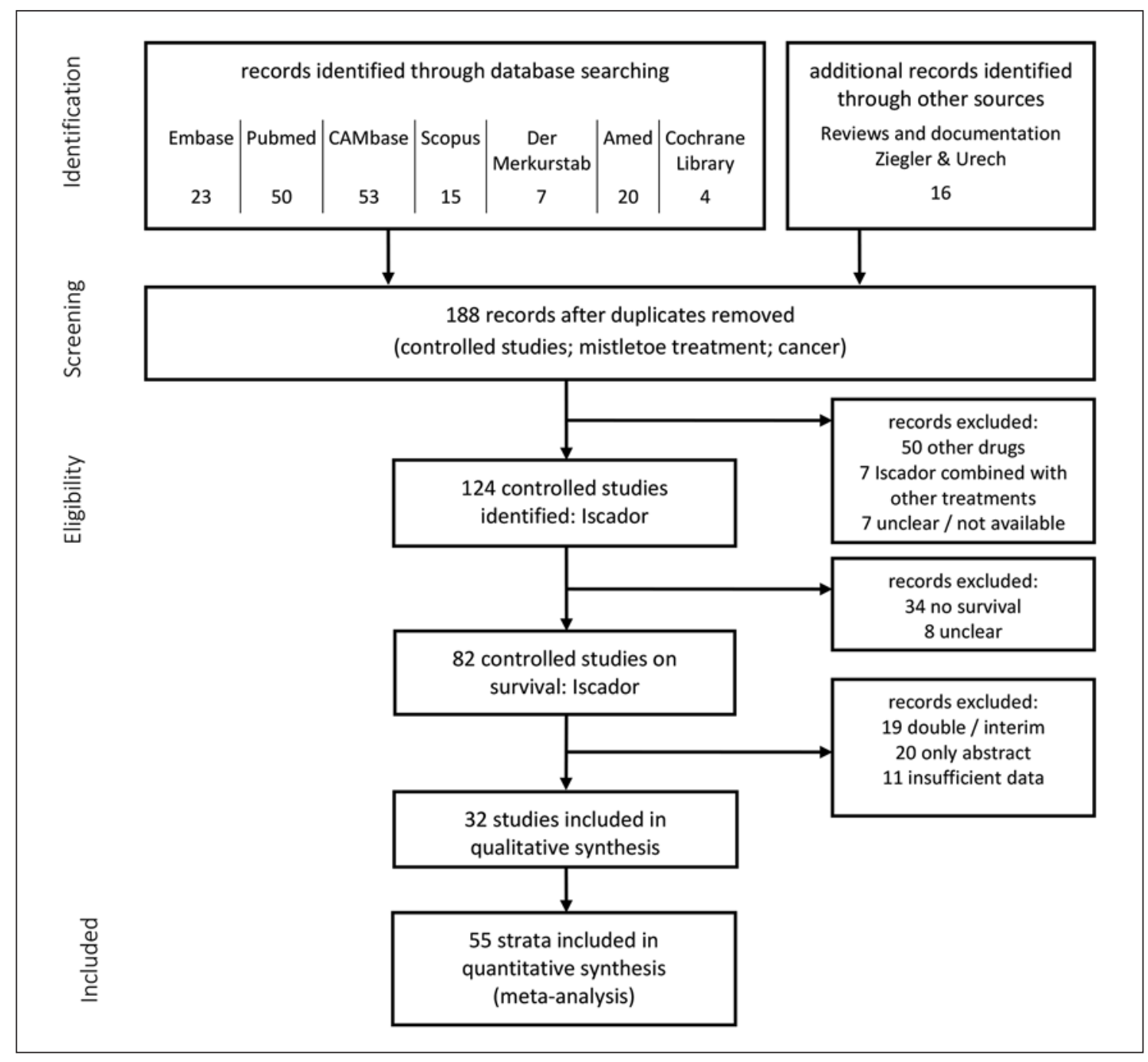

Fig. 1. Flow chart on the study inclusion/exclusion process.

these, 19 studies were excluded because of double publication or interim analyses, 20 were only abstracts, and 11 provided insufficient data. Thus, finally 32 studies from 1963 to 2014 with 56 strata provided adequate data for meta-analysis (Fig. 1).

\section{Study Design, Intervention Characteristics and \\ Patients}

The selected 32 studies with 55 strata included a total of 13,745 patients. Iscador was applied subcutaneously in all studies. Study sample sizes ranged from 20 to 3,075 patients per study (median 277). The major characteristics of the studies are shown in Table 1 (an extended list of study characteristics is provided as online suppl. Table N, see www.karger.com/doi/10.1159/000505202).

Twenty-four studies had a prospective design, 2 a retrolective design, and 12 a retrospective design (particularly the old studies). Randomization was done in 14 studies; particularly the older studies did not randomize the included patients. Exclusively the studies of Grossarth-Maticek et al. [22-29] had a matched-pair design, all others did not. Unfortunately, not all studies reported which type of Iscador (i.e., host tree specification) was subcutaneously applied, and thus we were unable to perform subgroup analyses on host tree effects.

\section{Subgroup Analyses}

The majority of studies reported positive effects in favour of Iscador. Heterogeneity of study results was moderate but significant $\left(I^{2}=50.9 \% ; p<0.0001\right)$, and the between-study variance was $\tau^{2}=0.053$; hence, a randomeffects model approach was chosen. The analysis revealed an overall HR of 0.59 (CI: [0.53; 0.65], $p<0.0001$; Fig. 2).

Subgroup analysis numerically showed less effects of randomized studies $(\mathrm{HR}=0.68$; CI: $[0.55 ; 0.83])$ compared with non-randomized studies ( $\mathrm{HR}=0.56$; $\mathrm{CI}$ : [0.50; $0.62])$, without being significantly different $(p=0.13)$. Other subgroup analyses showed no significant difference 
Table 1. Study characteristics

\begin{tabular}{|c|c|c|c|c|}
\hline First author [ref.], year & Design & Tumour & $N$ (verum/control) & Host tree \\
\hline Longhi [38], 2014 & RCT & Osteosarcoma & $9 / 11$ & $\mathrm{P}$ \\
\hline Bar-Sela [37], 2013 & RCT & Lung & $33 / 39$ & $\mathrm{Qu}$ \\
\hline Tröger [33], 2013 & RCT & Pancreas & $110 / 110$ & $\mathrm{Qu}$ \\
\hline Zänker [36], 2012 & RCS & Colorectal & $106 / 212$ & $\mathrm{Qu}$ \\
\hline Matthes [35], 2010 & RCS & Pancreas & $201 / 195$ & na \\
\hline Grossarth-Maticek [29], 2008 & RCT & Corpus uteri & $56 / 56$ & na \\
\hline Grossarth-Maticek [29], 2008 & PCS & Corpus uteri & $198 / 198$ & na \\
\hline Grossarth-Maticek [26], 2007 & RCT & Ovarian & $41 / 41$ & na \\
\hline Grossarth-Maticek [26], 2007 & PCS & Ovarian & $137 / 137$ & na \\
\hline Grossarth-Maticek [27], 2007 & RCT & Skin & $22 / 22$ & na \\
\hline Grossarth-Maticek [27], 2007 & PCS & Skin & $32 / 32$ & na \\
\hline Grossarth-Maticek [28], 2007 & RCT & Cervical & $19 / 19$ & na \\
\hline Grossarth-Maticek [28], 2007 & PCS & Cervical & $168 / 168$ & na \\
\hline Grossarth-Maticek [25], 2006 & PCS & Breast & $122 / 122$ & na \\
\hline Grossarth-Maticek [48], 2006 & RCT & Breast local & $17 / 17$ & na \\
\hline Grossarth-Maticek [48], 2006 & PCS & Breast regional & $42 / 42$ & na \\
\hline Grossarth-Maticek [48], 2006 & PCS & $\begin{array}{l}\text { Breast lymph } \\
\text { nodes }\end{array}$ & $55 / 55$ & na \\
\hline Grossarth-Maticek [48], 2006 & PCS & Breast metastases & $83 / 83$ & na \\
\hline Augustin [47], 2005 & RCS & Skin & $329 / 357$ & $\mathrm{P}, \mathrm{M}$ or $\mathrm{Qu}$ \\
\hline Bock [46], 2004 & RCS & Breast & $710 / 732$ & na \\
\hline Grossarth-Maticek [24], 2004 & PCS & Various & $175 / 175$ & na \\
\hline Kleeberg [49], 2004 & RCT & Skin & $102 / 102$ & M \\
\hline Grossarth-Maticek [22], 2001 & PCS & Various & $396 / 396$ & na \\
\hline Grossarth-Maticek [23], 2001 & RCT & Various & $39 / 39$ & na \\
\hline Dold [50], 1991 & RCT & Lung & $114 / 113$ & U c. Hg, Qu c. Hg \\
\hline Salzer [51], 1991 & RCT & Lung & $86 / 97$ & na \\
\hline Schuppli [52], 1990 & PCS & Skin & $84 / 114$ & P c. Hg + BCG \\
\hline Salzer [53], 1983 & RCT & Stomach & $35 / 37$ & na \\
\hline Hoffmann [54], 1982 & RCS & Breast & $254 / 482$ & na \\
\hline Leroi $[55], 1982^{\mathrm{a}}$ & HCT & Ovarian & $49 / 3,026$ & na \\
\hline Hoffmann [44], 1979 & RCS & Liver met & $188 / 122$ & na \\
\hline Leroi [45], 1979 & RCS & Colorectal & $101 / 54$ & na \\
\hline Salzer [56], 1978 & NRCT & Lung & $37 / 40$ & na \\
\hline Leroi [43], 1977 & RCS & Breast & $319 / 228$ & na \\
\hline Leroi [42], 1975 & RCS & Breast & $81 / 30$ & na \\
\hline Günczler [41], 1969 & CBA & Breast & $257 / 153$ & na \\
\hline Günczler [40], 1968 & RCS & Stomach & $67 / 101$ & na \\
\hline Fellmer [39], $1968^{\mathrm{a}}$ & Q-RCT & Cervical & $81 / 709$ & M c. Ag \\
\hline Majewski [31], 1963 & Q-RCT & Gynaecological & $72 / 52$ & na \\
\hline
\end{tabular}

RCT, randomized controlled trial; RCS, retrospective cohort study; Q-RCT, quasi-randomized controlled trial; PCS, prospective cohort study; NRCT, non-randomized controlled trial; HCT, historically controlled trial; CBA, controlled before-and-after study; BCG, Bacille Calmette-Guérin; M, Iscador M; P, Iscador P; Qu, Iscador $\mathrm{Qu}$; c., cum; Ag, Argentum; Hg, Hydrargyrum; na, not available. ${ }^{a}$ This study used a large number of control patients from the literature. The group of patients with Iscador was much smaller.

$(p=0.33)$ between newly included studies (since 2009) $(\mathrm{HR}=0.52 ; \mathrm{CI}:[0.43 ; 0.63])$ and former studies from our first review published in 2009 ( $\mathrm{HR}=0.65$; CI: [0.61; 0.69]). Meta-regression did not reveal an effect of sample size on the HR $(\beta=0.0001[-0.0002 ; 0.0004], p=0.37)$, or of publication year $(\beta=-0.0044[-0.0110 ; 0.0021], p=0.19)$ (Fig. 3). Further subgroup analysis for cancer entities (Table 2) showed higher $\mathrm{HR}$ for skin $(\mathrm{HR}=0.73)$ and lung cancer $(\mathrm{HR}=0.84)$ and lower HR for cervical cancer $(\mathrm{HR}=0.43)$. Meta-regression for cancer entities only showed significant differences of lung cancer $(\beta=0.38$; CI $[0.05 ; 0.71], p=0.03)$ from the reference class (breast cancer, $\mathrm{HR}=0.54, \beta=-0.58$; CI $[-0.75 ;-0.41]$ ) (Table 2). However, because these studies included different endpoints (overall survival, disease-free survival), a wide range of cancer stages and different study methodologies, these differences should be interpreted with caution.

Finally, the funnel plot (Fig. 4) was investigated for asymmetry. Although visual inspection seemed to in- 
Longhi (2014) [38]

Bar-Sela (2013) [37]

Bar-Sela (2013) [37]

Tröger (2013) [33]

Zaenker (2012) [36]

Matthes (2010) [35]

Grossarth-M. (2008) [29]

Grossarth-M. (2008) [29]

Grossarth-M. (2008) [29]

Grossarth-M. (2008) [29]

Grossarth-M. (2007) [26]

Grossarth-M. (2007) [26]

Grossarth-M. (2007) [26]

Grossarth-M. (2007) [26]

Grossarth-M. (2007)a [27]

Grossarth-M. (2007)a [27]

Grossarth-M (2007)b [28]

Grossarth-M (2007)b [28]

Grossarth-M (2007)b [28]

Grossarth-M (2006) a [25]

Grossarth-M (2006) a [25]

Grossarth-M. (2006) b [48]

Grossarth-M. (2006) b [48]

Grossarth-M. (2006) b [48]

Grossarth-M. (2006) b [48]

Augustin (2005) [47]

Bock (2004) [46]

Grossarth-M. (2004) [24]

Kleeberg (2004) [49]

Grosssarth-M (2001) [22]

Grosssarth-M (2001) [23]

Dold (1991) [50]

Salzer (1991) [51]

Schuppli (1990) [52]

Salzer \& Havelec (1983) [53]

Hoffmann \& Hajto (1982) [54]

Hoffmann \& Hajto (1982) [54]

Leroi \& Hajto (1982) [55]

Leroi \& Hajto (1982) [55]

Salzer \& Havelec (1978) [56]

Salzer \& Havelec (1978) [56]

Salzer \& Havelec (1978) [56]

Hoffmann (1979) [44]

Leroi (1979) [45]

Leroi (1977) [43]

Leroi (1977) [43]

Leroi (1975) [42]

Günczler \& Salzer (1969) [41]

Fellmer $(1966,1967,1968)[58,39]$

Günczler, Orsika \& Salzer (1968) [40]

Günczler, Orsika \& Salzer (1968) [40]

Majewski \& Bentele (1963) [31]

Majewski \& Bentele (1963) [31]

Majewski \& Bentele (1963) [31]

Majewski \& Bentele (1963) [31]

RE Model
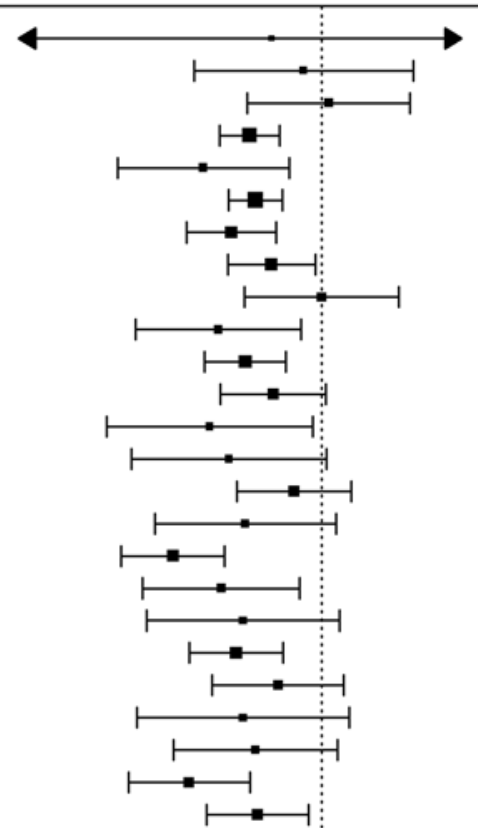

$\longmapsto$

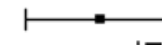

$\mathrm{H}=\mathrm{H}$
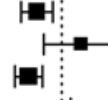

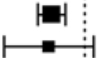

$\longmapsto=\vdots \begin{gathered}1 \\ \vdots\end{gathered}$

$1 \div$

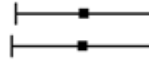

$\mapsto-1$

$\mapsto$
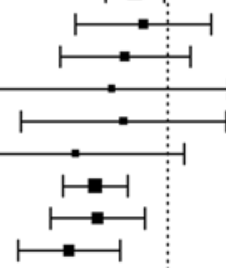

$\longmapsto-1$
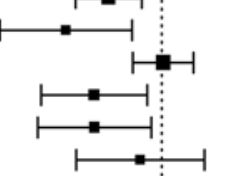

$1.40[0.40,4.94]$

$0.10[0.01,1.53]$

$0.49[0.10,2.45]$

$1.45[0.46,4.56]$

$0.59[0.53,0.65]$

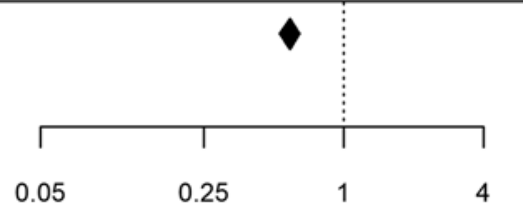

Observed Outcome

Fig. 2. Data of meta-analysis. The overall HR was 0.59 (CI: [0.54; 0.65$], p<0.0001)$. 


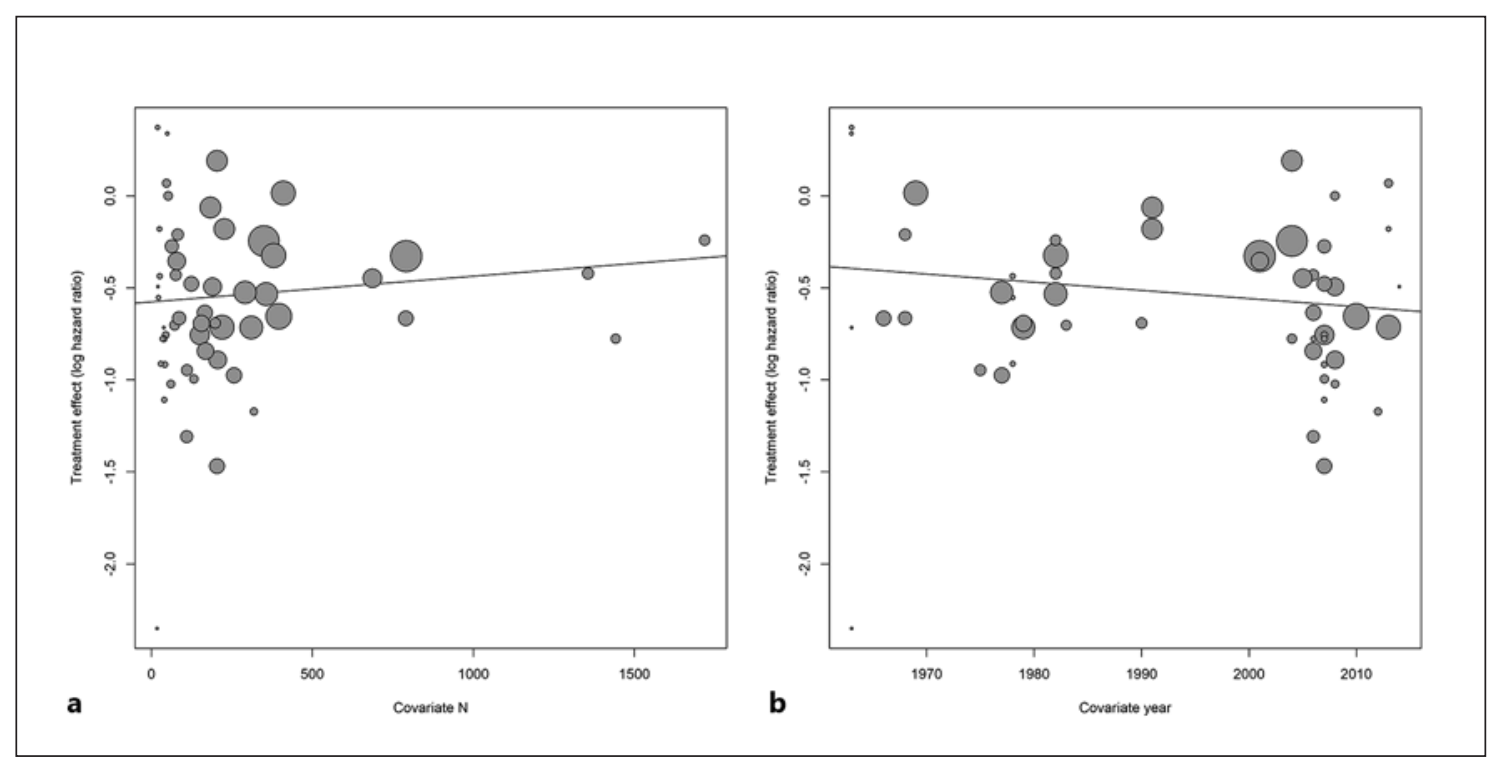

Fig. 3. Meta-regression effects for sample size (a) and year of publication (b).

Table 2. Meta-regression effects (log scale) for cancer entities and subgroup analysis for a random-effects model

\begin{tabular}{lllll}
\hline & $\beta(95 \% \mathrm{CI})$ & $p$ value & Studies & HR $(95 \% \mathrm{CI})$ \\
\hline Reference: breast & $-0.58(-0.75 ;-0.41)$ & $<0.0001$ & 14 & $0.54(0.45 ; 0.66)$ \\
Cervical & $-0.34(-0.73 ; 0,05)$ & $\mathrm{ns}$ & 5 & $0.43(0.26 ; 0.70)$ \\
Colorectal & $-0.25(-0.77 ; 0.27)$ & $\mathrm{ns}$ & 2 & $0.45(0.30 ; 0.67)$ \\
Corpus uteri & $-0.07(-0.44 ; 0.30)$ & $\mathrm{ns}$ & 5 & $0.52(0.35 ; 0.77)$ \\
Liver metastases & $-0.14(-0.64 ; 0.37)$ & $\mathrm{ns}$ & 1 & $0.49(0.35 ; 0.68)$ \\
Lung & $0.38(0.05 ; 0.71)$ & 0.03 & 7 & $0.84(0.67 ; 1.05)$ \\
Osteosarcoma & $0.09(-4.69 ; 4.86)$ & $\mathrm{ns}$ & 1 & $0.61(0.01 ; 71.27)$ \\
Ovarian & $0.03(-0.30 ; 0.36)$ & $\mathrm{ns}$ & 7 & $0.57(0.45 ; 0.73)$ \\
Pancreas & $-0.10(-0.46 ; 0.25)$ & $\mathrm{ns}$ & 2 & $0.51(0.42 ; 0.62)$ \\
Skin & $0.30(-0.03 ; 0.63)$ & $\mathrm{ns}$ & 5 & $0.73(0.51 ; 1.05)$ \\
Stomach & $0.05(-0.39 ; 0.50)$ & $\mathrm{ns}$ & 3 & $0.59(0.41 ; 0.85)$ \\
Various & $0.28(-0.01 ; 0.57)$ & $\mathrm{ns}$ & 3 & $0.74(0.67 ; 0.82)$ \\
\hline
\end{tabular}

ns, not significant; HR, hazard ratio; CI, confidence interval.

dicate no asymmetry in the upper region of the funnel plot, a value of $z=-1.8356$ in Egger's test for funnel plot asymmetry was found not to be significant ( $p=$ $0.066)$.

Quality Assessment of the Randomized Studies

Table 3 presents the review authors' judgements about each risk of bias item across included randomized studies. It shows that there was a relatively low risk of selection bias stemming from random sequence generation. Thus, there is a low risk of selection bias.

Furthermore, there was no blinding of participants and personnel. Therefore, there is a risk of performance bias due to knowledge of the allocated interventions by participants and personnel during the studies. A detec- tion bias is unlikely in studies on overall survival, but it may exist for event-free survival outcomes.

The risks for attrition bias as well as reporting bias are deemed to be quite low. In most included randomized controlled trials (RCTs), there was no concern over the amount, nature or handling of incomplete outcome data. Similarly, only a very small risk for selective outcome reporting was found. These results are mostly contrary to those of a recent review [30]. This may be due to our strict compliance with the Cochrane Handbook for Systematic Reviews of Interventions, version 5.2.0. [18].

Quality Assessment of the Non-Randomized Studies

Table 4 presents the review authors' judgements about each risk of bias item across included non-randomized 


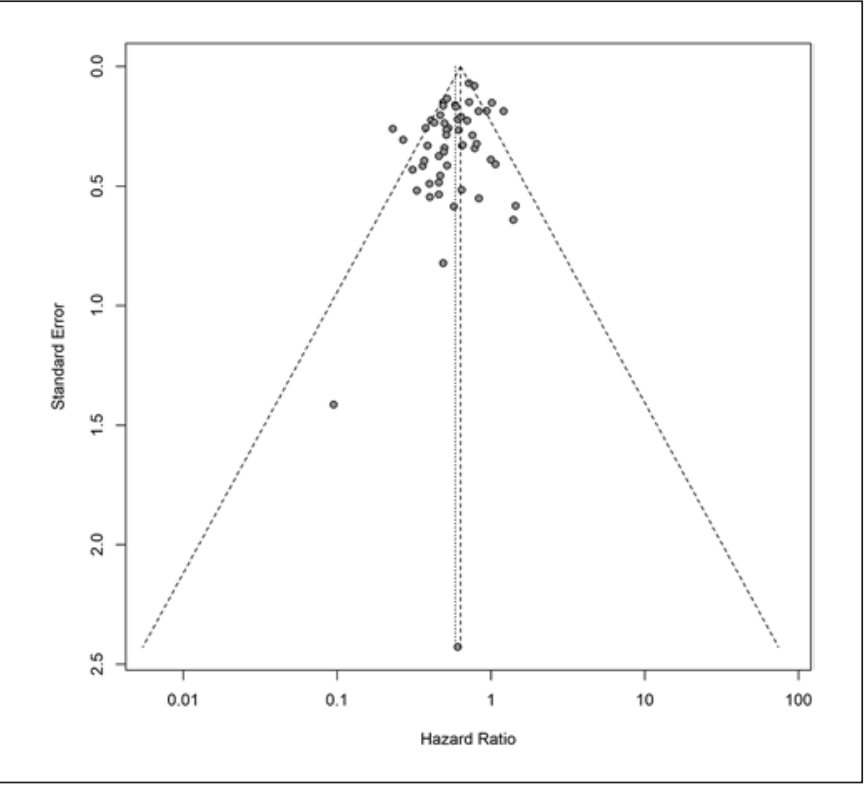

Fig. 4. Funnel plot analysis.

studies using the Newcastle-Ottawa scale. It shows that the majority of the included studies are of good quality and reached the maximum score of the scale, whereas the studies older than 40 years were of minor quality. This may be due to the fact that there were no quality guidelines at that time. Primary concerns were the inadequate allocation of patients to the mistletoe or control groups and, in consequence, an inferior comparability even when subgroup or stratified analyses were presented.

\section{Discussion}

This is an extended update of our 2009 review on the survival data of cancer patients treated with Iscador extracts. It includes 5 new studies with 6 strata. The overall HR was 0.59 (CI: $[0.54 ; 0.65], p<0.0001)$ and is thus similar to that of our 2009 review ( $\mathrm{HR}=0.59$; CI: [0.53; 0.66], $p<0.0001$ ). Interestingly, survival data of 3 of 6 new strata were in favour of Iscador, whilst 3 were not; the HR of these 6 new strata is $0.53(0.43 ; 0.65)$. Although this value is slightly "better" than the overall HR, the difference is not statistically significant $(\mathrm{Q}=1.25 ; p=0.265)$.

Our primary aim was the integration of all available evidence, while the impact of confounders, such as differing study designs or misleading bias, was assessed only subsequently in separate stratified and sensitivity analyses, e.g., randomized and non-randomized studies in general examine the different objectives of clinical efficacy and effectiveness, respectively, and therefore differences in HR might be expected. We are aware that both the age of the included studies and thus methodology and quality of studies has a wider range. Therefore, we performed different subgroup analyses to address this. However, neither randomization status (yes/no) nor sample size showed a significant effect on the study outcomes. Because tumour localisation may also be a crucial point, we first analysed the general treatment effect and then performed analyses with respect to the tumour localisations. We found that cancer entities had an effect on the reported outcomes, with a better effect for cervical cancer $(\mathrm{HR}=0.43)$ and less relevant effects for lung cancer $(H R=0.84)$. Different numbers of studies with tumour entities that respond better or worse to mistletoe therapy can simulate a publication bias in the funnel plot. Funnel plot analysis for asymmetry was not significant with $z=-1.881, p=0.06$. As can be seen in Figure 4, funnel plot asymmetry is mostly due to a retrospective study from 1963 [31] denoting an extreme outlier in the lower left side of the funnel plot.

With respect to quality assessment, none of the studies was blinded and, therefore, there might be performance bias due to knowledge of the allocated interventions by participants and personnel during the study. However, this bias is estimated to be small when survival is the endpoint. Therefore, in the FDA guidelines, blinding in survival studies is not an obligatory need [32]. In summary, across trials and across domains, there was a small to medium risk of bias, meaning that the risk of bias could raise some doubt about the positive results. For more detail, Table 3 gives an overview of the review authors' judgements about each risk of bias item for included randomized studies.

\section{Results from Recent Studies}

A major problem in judging the effect is that several of the included studies were rather old and used anti-cancer treatment regimens which in general are not used anymore. Therefore, it is important to underline that the treatment effects of the more recent studies are similar to those of the old studies.

One of the recent studies is the 2013 RCT by Tröger et al. [33] from 2013 which was performed in Serbia. They included patients with advanced or metastatic pancreatic cancer who were receiving no further treatment "other than best supportive care." Patients in the control group had more contacts to the physicians than patients in the mistletoe group. Nevertheless, the treatment benefit for the Iscador group with respect to survival [33] and quality of life [34] also was significantly better. The median overall survival was 2 months longer in the Iscador group compared to the control group ( 4.8 vs. 2.7 months; $\mathrm{HR}=$ $0.49 ; p<0.0001)$.

In 2010, Matthes et al. [35] published a controlled, retrospective study comparing patients with pancreatic carcinoma from Germany or Switzerland treated between 1993 and 2002 with gemcitabine plus Iscador or gemcitabine alone (or any other best of care). In this study, the 
Table 3. Risk of bias summary: review authors' judgements about each risk of bias item for each included randomized study

\begin{tabular}{|c|c|c|c|c|c|c|}
\hline First author [ref.], year & $\begin{array}{l}\text { Random } \\
\text { sequence } \\
\text { generation } \\
\text { (selection bias) }\end{array}$ & $\begin{array}{l}\text { Allocation } \\
\text { concealment } \\
\text { (selection bias) }\end{array}$ & $\begin{array}{l}\text { selective } \\
\text { reporting } \\
\text { (reporting bias) }\end{array}$ & $\begin{array}{l}\text { incomplete } \\
\text { outcome data } \\
\text { (attrition bias) }\end{array}$ & $\begin{array}{l}\text { Blinding of } \\
\text { participants and } \\
\text { personnel } \\
\text { (performance bias) }\end{array}$ & $\begin{array}{l}\text { Blinding of } \\
\text { outcome } \\
\text { assessment } \\
\text { (detection bias) }\end{array}$ \\
\hline Bar-Sela [37], 2013 & + & $?$ & + & $?$ & - & na \\
\hline Dold [50], 1991 & + & + & + & $?$ & - & na \\
\hline Grossarth-Maticek [24], 2004 & + & + & + & + & - & na \\
\hline Grossarth-Maticek [25], 2006a & + & + & + & + & - & na \\
\hline Grossarth-Maticek [48], 2006b & + & + & + & + & - & na \\
\hline Grossarth-Maticek [28], 2007a & + & + & + & + & - & na \\
\hline Grossarth-Maticek [26], 2007b & + & + & + & + & - & na \\
\hline Grossarth-Maticek [27], 2007c & + & + & + & + & - & na \\
\hline Grossarth-Maticek [29], 2008 & + & + & + & + & - & na \\
\hline Grossarth-Maticek [22], 2001 & + & + & + & + & - & na \\
\hline Kleeberg [49], 2004 & $?$ & + & + & + & - & na \\
\hline Longhi [38], 2014 & + & + & $?$ & + & - & na \\
\hline Salzer [56], 1983 & + & $?$ & + & + & - & na \\
\hline Salzer [51], 1991 & + & + & + & + & - & na \\
\hline Tröger [33], 2013 & + & + & + & + & - & na \\
\hline
\end{tabular}

+ , indicates an adequate performance (no risk); -, indicates a putatively negative performance (risk of bias); ?, indicates that the reviewer was not able to state it; na, means that it is not applicable in survival studies.

Table 4. Risk of bias summary: review authors' judgements about each risk of bias item for each included non-randomized study

\begin{tabular}{|c|c|c|c|c|}
\hline First author [ref.], year & $\begin{array}{l}\text { Selection domain } \\
(\max .4)\end{array}$ & $\begin{array}{l}\text { Comparability } \\
\text { domain (max. 2) }\end{array}$ & $\begin{array}{l}\text { Outcome/exposure } \\
\text { domain (max. } 3)\end{array}$ & $\begin{array}{l}\text { Overall score } \\
(\max .9)\end{array}$ \\
\hline Matthes [35], 2010 & $* * * *$ & $* *$ & $* * *$ & 9 \\
\hline Friedel [57], 2009 & $* * * *$ & $* *$ & $* *$ & 8 \\
\hline Grossarth-Maticek [29], 2008 & $* * * *$ & $* *$ & $* * *$ & 9 \\
\hline Grossarth-Maticek [29], 2008 & $* * * *$ & $* *$ & $* * *$ & 9 \\
\hline Grossarth-Maticek [28], 2007 & $* * * *$ & $* *$ & $* * *$ & 9 \\
\hline Grossarth-Maticek [28], 2007 & $* * * *$ & $* *$ & $* * *$ & 9 \\
\hline Grossarth-Maticek [26], 2007b & $* * * *$ & $* *$ & $* * *$ & 9 \\
\hline Grossarth-Maticek [26], 2007b & $* * * *$ & $* *$ & $* * *$ & 9 \\
\hline Grossarth-Maticek [27], 2007c & $* * * *$ & $* *$ & $* * *$ & 9 \\
\hline Grossarth-Maticek [25], 2006 & $* * * *$ & $* *$ & $* * *$ & 9 \\
\hline Grossarth-Maticek [48], 2006b & $* * * *$ & $* *$ & $* * *$ & 9 \\
\hline Grossarth-Maticek [48], 2006b & $* * * *$ & $* *$ & $* * *$ & 9 \\
\hline Grossarth-Maticek [48], 2006b & $* * * *$ & $* *$ & $* * *$ & 9 \\
\hline Augustin [47], 2005 & $* * * *$ & $* *$ & $* * *$ & 9 \\
\hline Bock [46], 2004 & $* * * *$ & ** & $* * *$ & 9 \\
\hline Leroi [55], 1982 & $* *$ & & $* *$ & 4 \\
\hline Salzer [56], 1978 & $* * * *$ & $*$ & $* * *$ & 8 \\
\hline Fellmer [58], 1966 & $* * * *$ & $* *$ & $* *$ & 7 \\
\hline Leroi $[45], 1979$ & $* * * *$ & & $* *$ & 6 \\
\hline Günczler [41], 1969 & $* * *$ & & $* * *$ & 6 \\
\hline Majewski [31], 1963 & $* * * *$ & & * & 5 \\
\hline Hoffmann [54], 1982 & $* *$ & & $* *$ & 5 \\
\hline Hoffmann [44], 1979 & $* * * *$ & $*$ & $* *$ & 7 \\
\hline Leroi [43], 1977 & $* * * *$ & $*$ & $* *$ & 7 \\
\hline Günczler [40], 1968 & $* * * *$ & & $* * *$ & 7 \\
\hline Leroi [42], 1975 & $* * *$ & $*$ & $* *$ & 6 \\
\hline
\end{tabular}


HR was 0.52 (CI: 0.40 to $0.68 ; p<0.001$ ), indicating that patients treated with Iscador plus gemcitabine may have a survival benefit. The same group published in 2012 data of a retrospective observational cohort study and reported a HR of 0.31 (CI: 0.13 to $0.71 ; p=0.006$ ), which indicates a benefit of Iscador treatment in patients with colorectal carcinoma [36]. However, both studies had a retrospective design and were not prospectively randomized; to overcome this potential bias, they performed systematic multivariable adjusting of end point criteria.

Bar-Sela et al. [37] in 2013 performed an RCT in chemotherapy-naive advanced non-small cell lung cancer patients treated with Iscador and carboplatin-based combinations, or with carboplatin-based combinations alone. Here, the median time to progression was 4.8 months versus 6 months, indicating no significant differences between the groups, but for stage III and stage IV patients. However, the numbers of severe non-haematological side effects and hospitalizations were lower in the Iscador group, and thus further research with respect to chemotherapy tolerability might be interesting.

A recent RCT from 2014 compared adjuvant Iscador application versus oral etoposide in 20 osteosarcoma patients [38]. Here, the 12-month post-relapse disease-free survival was 4 months (range 1-47) in the etoposidetreated group $(n=11)$ and 39 months (range $2-73)$ in the Iscador group $(n=9)$. However, the treatment group is rather small, and thus no valid conclusions can be drawn.

Therefore, the conclusions that can be drawn from the recent 5 studies published since 2010 are still vague. Besides the impressive results for the survival of pancreatic cancer patients [33], the study with osteosarcoma showed good results but was small [38]. One study found no significant benefit in survival (lung cancer) [37]. The 2 remaining studies showed a significant prolongation of survival in favour of Iscador (colon, pancreas) $[35,36]$ but were retrospective studies.

\section{Limitations}

A limitation of this meta-analysis is that the pooled estimates are based on quite heterogeneous data and from a long period of time (1963-2014). Several of the studies used study designs, analytical methods and treatment regimens which are out of date [31, 39-47], but they are important for the completeness of this systematic analysis. Therefore, our study pool is a composite of quite different studies. Recent studies are often methodologically "better" than older studies as is indicated by the lack of RCTs before 1983 and the poor quality assessment of those early studies. Nevertheless, stratified analysis suggests that the year of publication ("age") has no significant effect on the reported outcome. Furthermore, in this sample, RCTs did not show significantly lower survival effects than non-RCTs.
A further limitation of the study is that we have to deal with several bias factors which may weaken the evidence of the studies, particularly performance bias due to knowledge of the allocated interventions by participants and personnel, while the risks for attrition or reporting bias seem to be low. Some of the older studies may be biased by selection of patients, as discussed. There are studies which included patients with metastatic disease who had already lived for at least 15 more months before they were included in the study and were then compared with patients who may have already died in this time span. This could be regarded as a survival benefit which is in fact due to selection. Therefore, we performed subgroup analyses with respect to randomization versus non-randomization, year of publication (implying that the old studies were of poorer methodological quality than the new ones), and sample size (implying that small studies would have better effects than larger studies).

\section{Conclusion}

Compared to the first analysis in 2009, we found almost identical effects in cancer survival based on a broader database of higher quality. Study type (randomized vs. non-randomized) did not influence the results of the meta-analysis; further, there was no effect of sample size, but there were hints for moderate publication bias. However, the publication bias can be an effect of the joint evaluation of many tumour entities: in the course of time, studies may have been repeated with those tumour entities that were more likely to be successful. The data underline that adjuvant treatment of cancer patients with the mistletoe extract Iscador can be associated with a better survival. One may consider it as a second-line treatment, which may have distinct effectiveness in different tumour entities. Nevertheless, studies based on sound methodological designs and modern anti-tumour therapies are needed to establish the promising findings of studies published within more than 50 years.

\section{Statement of Ethics}

The authors have no ethical conflicts to declare.

\section{Disclosure Statement}

T.O. and A.B. received financial support by a grant of Förderverein komplementärmedizinische Forschung, Arlesheim (Switzerland), to perform this meta-analysis. None of the authors is employed at a pharmaceutical company or received consultation fees or is in an advisory board or board of directors or other type of management relationships with such companies. The authors have no competing interests and were free to interpret the data according to a strict scientific rationale. 


\section{Funding Sources}

Förderverein komplementärmedizinische Forschung, Arlesheim (Switzerland), provided financial support to perform this meta-analysis.

\section{Author Contributions}

A.B. and T.O. initiated and oversaw the project and contributed to the design of the manuscript. D.P. and C.R. did the literature research, and D.P. entered the data. T.O., S.A. and K.B. did the statistical analysis. D.P., S.A., T.O. and A.B. drafted the manuscript. All authors read and approved the final manuscript.

\section{References}

1 World Health Organization. Global Status report on non-communicable diseases 2014: attaining the nine global non-communicable diseases targets; a shared responsibility. Geneva: World Health Organization; 2014.

2 Horneber M, Bueschel G, Dennert G, Less D, Ritter E, Zwahlen M. How many cancer patients use complementary and alternative medicine: a systematic review and metaanalysis. Integr Cancer Ther. 2012 Sep;11(3):187203.

$3 \mathrm{NCCIH}$, National Center for Complementary and Integrative Health. Complementary, Alternative, or Integrative Health: What's in a Name? [Internet]. 2011. Available from: https://nccih.nih.gov/health/integrativehealth

4 Kooreman P, Baars EW. Patients whose GP knows complementary medicine tend to have lower costs and live longer. Eur J Health Econ. 2012 Dec;13(6):769-76.

5 Widhalm S. Die Mistelgabe in der Tumortherapie: was gibt's Neues? Z Phytother. 2013; 34(03):112-5

6 Kalder M, Müller T, Fischer D, Müller A, Bader W, Beckmann MW, et al. A Review of Integrative Medicine in Gynaecological Oncology. Geburtshilfe Frauenheilkd. 2016 Feb; 76(2):150-5.

7 Steiner R. Geisteswissenschaft und Medizin: 20 Vorträge, gehalten in Dornach vom 21. März bis 09. April 1920 vor Ärzten und Medizinstudenten. Dornach: Rudolf Steiner Verlag; 1985.

8 Becker H. Botany of European mistletoe (Viscum album L.). Oncology. 1986;43(1 Suppl 1): 2-7.

9 Büssing A. Overview on Viscum album L. products. In: Büssing A, editor. Mistletoe: The Genus Viscum. Amsterdam: Harwood Academic Publishers; 2000. pp. 209-21.

10 Zeylmans van Emmichoven JE. Wer war Ita Wegman ? Bd. 1, 1876 bis 1925. Dornach: Verlag am Goetheanum; 1990.

11 Steele ML, Axtner J, Happe A, Kröz M, Matthes H, Schad F. Adverse Drug Reactions and Expected Effects to Therapy with Subcutaneous Mistletoe Extracts (Viscum album L.) in Cancer Patients. Evid Based Complement Alternat Med. 2014;2014:724258.

12 Ostermann T, Raak C, Büssing A. Survival of cancer patients treated with mistletoe extract (Iscador): a systematic literature review. BMC Cancer. 2009 Dec;9(1):451-60.

13 Büssing A, Raak C, Ostermann T. Quality of life and related dimensions in cancer patients treated with mistletoe extract (Iscador): a meta-analysis. Evid Based Complement Alternat Med. 2012;2012:219402.
14 Marvibaigi M, Supriyanto E, Amini N, Abdul Majid FA, Jaganathan SK. Preclinical and clinical effects of mistletoe against breast cancer. Biomed Res Int. 2014;2014:785479.

15 Büssing A, Suzart K, Schweizer K. Differences in the apoptosis-inducing properties of Viscum album L. extracts. Anticancer Drugs. 1997 Apr;8(1 Suppl 1):S9-14.

16 Ziegler R, Urech K. Dokumentation publizierter klinischer Studien mit Iscador. 2016.

17 Moher D, Liberati A, Tetzlaff J, Altman DG; PRISMA Group. Preferred reporting items for systematic reviews and meta-analyses: the PRISMA statement. Ann Intern Med. 2009 Aug;151(4):264-9.

18 Higgins JP, Altman DG, Sterne JA. Chapter 8: Assessing risk of bias in included studies. In: Higgins JPT, Churchill R, Chandler J, Cumpston MS, editors. Cochrane Handbook for Systematic Reviews of Interventions. Cochrane; 2017.

19 Wells GA, Shea B, O'Connell D. The Newcastle-Ottawa Scale (NOS) for assessing the quality of nonrandomised studies in meta-analyses. Ottawa (ON): Ottawa Hospital Research Institute; 2013.

20 Tierney JF, Stewart LA, Ghersi D, Burdett S, Sydes MR. Practical methods for incorporating summary time-to-event data into metaanalysis. Trials. 2007 Jun;8(1):16.

21 Schwarzer G. meta: an R package for metaanalysis. R News. 2007;7(3):40-5.

22 Grossarth-Maticek R, Kiene H, Baumgartner SM, Ziegler R. Use of Iscador, an extract of European mistletoe (Viscum album), in cancer treatment: prospective nonrandomized and randomized matched-pair studies nested within a cohort study. Altern Ther Health Med. 2001 May-Jun;7(3):57-66.

23 Grossarth Maticek R, Kiene H, Baumgartner S, Ziegler R. Verlängerung der Überlebenszeit von Krebspatienten unter Misteltherapie (Iscador). Ergebnisse einer epidemiologischen Langzeitstudie. Schweiz Zschr Ganzheitsmedizin. 2001;13(4):217-25

24 Grossarth-Maticek R, Kiene H, Baumgartner S, Ziegler R. Synergieeffekte von Selbstregulation und Misteltherapie (Iscador) auf die Überlebenszeit bei Krebspatienten. Schweiz Zschr Ganzheitsmedizin. 2004;16(2):81-9.

25 Grossarth-Maticek R, Ziegler R. Prospective controlled cohort studies on long-term therapy of breast cancer patients with a mistletoe preparation (Iscador). Forsch Komplementmed. 2006 Oct;13(5):285-92.

26 Grossarth-Maticek R, Ziegler R. Prospective controlled cohort studies on long-term therapy of ovarian cancer patients with mistletoe (Viscum album L.) extracts Iscador. Arzneimittelforschung. 2007;57(10):665-78.
27 Grossarth-Maticek R, Ziegler R. Wirksamkeit und Unbedenklichkeit einer Langzeitbehandlung von Melanompatienten mit einem Mistelpräparat (Iscador). Schweiz Zschr Ganzheitsmedizin. 2007;19(6):325-32.

28 Grossarth-Maticek R, Ziegler R. Prospective controlled cohort studies on long-term therapy of cervical cancer patients with a mistletoe preparation (Iscador). Forsch Komplementmed. 2007 Jun;14(3):140-7.

29 Grossarth-Maticek R, Ziegler R. Randomized and non-randomized prospective controlled cohort studies in matched pair design for the long-term therapy of corpus uteri cancer patients with a mistletoe preparation (Iscador). Eur J Med Res. 2008 Mar;13(3):107-20.

30 Freuding M, Keinki C, Micke O, Buentzel J, Huebner J. Mistletoe in oncological treatment: a systematic review: Part 1: survival and safety. J Cancer Res Clin Oncol. 2019 Mar; 145(3):695-707.

31 Majewski A, Bentele W. Über Zusatzbehandlung beim weiblichen Genitalkarzinom. Zentralbl Gynäkol. 1963;85(20):696-700.

32 FDA. Clinical Trial Endpoints for the Approval of Cancer Drugs and Biologics. Guidance for Industry [Internet]. 2018. Available from: https://www.fda.gov/media/71195/ download

33 Tröger W, Galun D, Reif M, Schumann A, Stanković N, Milićević M. Viscum album [L.] extract therapy in patients with locally advanced or metastatic pancreatic cancer: a randomised clinical trial on overall survival. Eur J Cancer. 2013 Dec;49(18):3788-97.

34 Tröger W, Galun D, Reif M, Schumann A, Stanković N, Milićević M. Quality of life of patients with advanced pancreatic cancer during treatment with mistletoe: a randomized controlled trial. Dtsch Arztebl Int. 2014 Jul;111(29-30):493-502.

35 Matthes H, Friedel WE, Bock PR, Zänker KS. Molecular mistletoe therapy: friend or foe in established anti-tumor protocols? A multicenter, controlled, retrospective pharmacoepidemiological study in pancreas cancer. Curr Mol Med. 2010 Jun;10(4):430-9.

36 Zänker KS, Matthes H, Bock PR, Hanisch J. A specific mistletoe preparation (Iscador-Qu) in colorectal cancer (CRC) patients: more than just supportive care? J Cancer Sci Ther. 2012;4(9):264-70.

37 Bar-Sela G, Wollner M, Hammer L, Agbarya A, Dudnik E, Haim N. Mistletoe as complementary treatment in patients with advanced non-small-cell lung cancer treated with carboplatin-based combinations: a randomised phase II study. Eur J Cancer. 2013 Mar;49(5): 1058-64. 
38 Longhi A, Reif M, Mariani E, Ferrari S. A Randomized Study on Postrelapse Disease-Free Survival with Adjuvant Mistletoe versus Oral Etoposide in Osteosarcoma Patients. Evid Based Complement Alternat Med. 2014;2014: 210198.

39 Fellmer KE. A clinical trial of Iscador. Br Homeopath J. 1968;57(01):43-7.

40 Günczler M, Osika C, Salzer G. Ergebnisse von Resektion und Nachbehandlung beim Magenkarzinom. Wien Klin Wochenschr. 1968 Feb;80(6):105-6.

41 Günczler M, Salzer G. Iscadortherapie in der Nachbehandlung operierter Carcinome. Osterr Arzteztg. 1969;24(20):2290-4.

42 Leroi R. Malignomtherapie mit neuen Iscador-Präparaten. Krebsgeschehen. 1975;7(5): 124-6.

43 Leroi R. Nachbehandlung des operierten Mammakarzinoms mit Viscum album. Helv Chir Acta. 1977 Jun;44(3):403-14.

44 Hoffmann J. Die Iscador-Behandlung bei Lebermetastasen. Krebsgeschehen. 1979;(6): 172-5.

45 Leroi R. Die Iscadorbehandlung bei inoperablen kolo-rektalen Tumoren. Krebsgeschehen. 1979;11(6):163-5

46 Bock PR, Friedel WE, Hanisch J, Karasmann M, Schneider B. Retrolective, comparative, epidemiological cohort study with parallel groups design for evaluation of efficacy and safety of drugs with "well-established use". Forsch Komplementarmed Klass Naturheilkd. 2004 Aug;11 Suppl 1:23-9.

47 Augustin M, Bock PR, Hanisch J, Karasmann M, Schneider B. Safety and efficacy of the long-term adjuvant treatment of primary intermediate- to high-risk malignant melanoma (UICC/AJCC stage II and III) with a standardized fermented European mistletoe (Viscum album L.) extract. Results from a multicenter, comparative, epidemiological cohort study in Germany and Switzerland. Arzneimittelforschung. 2005;55(1): 38-49.

48 Grossarth-Maticek R, Ziegler R. Randomised and non-randomised prospective controlled cohort studies in matched-pair design for the long-term therapy of breast cancer patients with a mistletoe preparation (Iscador): a reanalysis. Eur J Med Res. 2006 Nov;11(11): 485-95.

49 Kleeberg UR, Suciu S, Bröcker EB, Ruiter DJ, Chartier C, Liénard D, et al.; EORTC Melanoma Group in cooperation with the German Cancer Society (DKG). Final results of the EORTC 18871/DKG 80-1 randomised phase III trial. rIFN-alpha2b versus rIFN-gamma versus ISCADOR $M$ versus observation after surgery in melanoma patients with either high-risk primary (thickness $[\{\mathrm{GT}\}] 3 \mathrm{~mm}$ ) or regional lymph node metastasis. Eur J Cancer. 2004 Feb;40(3):390-402.

50 Dold U, Edler L, Mäurer H, Müller D, Sakellariou B, Trendelenburg F, et al. Krebszusatztherapie beim fortgeschrittenen nichtkleinzelligen Bronchialkarzinom. Multizentrische kontrollierte Studie zur Prüfung der Wirksamkeit von Iscador und Polyerga. Stuttgart, New York: G. Thieme Verlag; 1991. 51 Salzer G, Danmayr E, Wutzlhofer F, Frey S. Adjuvante Iscador-Behandlung operierter nicht kleinzelliger Bronchuskarzinome. Ergebnisse einer randomisierten Studie. Dtsch Z Onkol. 1991;23(4):94-8.

52 Schuppli R. Die adjuvante Behandlung des malignen Melanoms mit Iscador c. Hg. In Jungi WF, Senn HJ, editors. Krebs und Alternativmedizin II. Berlin, Heidelberg: Springer Verlag; 1990. p. 84-87.

53 Salzer G, Havelec L. Adjuvante Iscador-Behandlung nach operiertem Magenkarzinom. Ergebnisse einer randomisierten Studie. Krebsgeschehen. 1983;15(4):106-10.

54 Hoffmann J, Hajto T. Iscadorbehandlung beim metastasierenden Mammakarzinom. Krebsgeschehen. 1982;(3):71-5.

55 Leroi R, Hajto T. Die Iscadortherapie beim Ovarialkarzinom. Krebsgeschehen. 1982; 14(2):38-44.

56 Salzer G, Havelec L. Rezidivprophylaxe bei operierten Bronchuskarzinompatienten mit dem Mistelpräparat Iscador: Ergebnisse eines klinischen Versuchs aus den Jahren 1969-1971. Onkologie. 1978 Dec;1(6):264-

57 Friedel WE, Matthes H, Bock PR, Zänker KS Systematic evaluation of the clinical effects of supportive mistletoe treatment within chemo- and/or radiotherapy protocols and longterm mistletoe application in nonmetastatic colorectal carcinoma: multicenter, controlled, observational cohort study. J Soc Integr Oncol. 2009;7(4):137-45.

58 Fellmer C, Fellmer KE. Nachbehandlung bestrahlter Genitalkarzinome mit dem Viscum album-Präparat “Iscador". Krebsarzt. 1966; 21(3):174-85 